\title{
Effect of Garcinia Cambogia and Green Coffee Bean in Weight Reduction
}

\section{Authors}

1. Arshad Chohan

Obstetrics and Gynaecology, Craft Institute of Reproduction and Fertility Treatment, Lahore

marshadchohan@hotmail.com

2. Tayyiba Wasim

Obstetrics and Gynaecology, Services Hospital Lahore, Lahore

tayyibawasim@yahoo.com

3. Shahid Irshad Rao

Obstetrics and Gynaecology, Nishter Hospital and Medical University, Multan drshahidrao@hotmail.com

4. Jahan Ara Hassan

Internal Medicine, Dow University of Health Sciences, Karachi jahanaraainuddin@yahoo.com

5. Nasira Tasneem

Obstetrics and Gynaecology, Pakistan Institute of Medical Sciences, Islamabad mchunit2@gmail.com

6. Tasnim Z. Ali

Nutrition, Wilcare Medical Center, Lahore

rdn.wilcare@gmail.com

7. Faizan Shaukat

Jinnah Post Graduate Medical Center, Karachi

Faizan.shaukat89@gmail.com 


\begin{abstract}
Introduction:

Various studies have widely documented how weight (being overweight, underweight or obese) plays a significant role in increasing health problems and adversely affects the quality of life. Out of all the weight-related issues, obesity is the number one contributing factor for causing health problems. To overcome this factor, a trial was conducted where a drug 'Lite plus' (Garcinia Cambogia and Green Coffee bean) was given to a select number of people for a period of three months.
\end{abstract}

\title{
Materials and Methods:
}

'Lite Plus' is a drug which contains Garcinia cambogia $500 \mathrm{mg}+$ Green Coffee Bean Extract 400 $\mathrm{mg}$, with a recommended dosage of 2 tablets/day with or before meals for 3 months. Most of the patients included in our study were females suffering from obesity-related problems such as PCOs and Infertility. During the trial, all patients were given the recommended dosage of 'Lite plus', while those with diabetes had the dose amended accordingly.

\section{Results:}

As a result of this trial, it was found that the use of 'Lite Plus' was very effective in decreasing weight/BMI with continuous use. After 6 weeks, out of the 250 respondents participating in the trial, 232 got a reduction in their BMI, and after 12 weeks (end of the trial), 29 respondents (11.6\%) reached the desired level of BMI.

\section{Conclusion:}

Garcinia cambogia and Green Coffee bean are effective and safe in weight reduction.

\section{Keywords:}

Garcinia cambogia, Green Coffee bean, Pakistan, Weight loss, Obesity 


\section{Introduction}

The Body Mass Index (BMI) is directly related to the bodyweight of a person, and therefore an increase or decrease in body weight results in an increase or decrease of the BMI, respectively. For clarity, we shall use the WHO's criteria for categorizing based on weight. According to the World Health Organization (WHO), an adult with a Body Mass Index (BMI) between 18.5 and 24.9 is considered to have a healthy weight, while those having a BMI value below 18.5 are considered underweight, those with a BMI value between 25 and 29.9 are considered overweight, and an adult with a BMI of 30 or more is considered obese [1]. This trial focuses on people falling under the two latter categories, i.e. overweight and obese.

Excessive weight gain is a serious health concern globally. Obesity has been a documented risk factor of chronic diseases like Hypertension, Type II Diabetes, Cardiovascular disease, Polycystic Ovarian Syndrome (PCOS) and Infertility. According to the National Nutrition Survey 2018 (NNS), the prevalence of overweight and obese women is increasing in Pakistan. In 2011, 28\% people were reported to be overweight and obese; however, the percentage rose to 37.8 in 2018 [2].

To combat this increasing prevalence, several medicines and weight loss treatments are available. Our trial is based on the use of organic products like Garcinia cambogia and green coffee bean extract to achieve weight loss. Garcinia cambogia, previously known as Gummi gata, is a South-East Asian fruit found in countries like India and China. It is popularly used as a culinary ingredient for flavouring and preservation, but it has some therapeutic uses as well. It has been used as a treatment for constipation, piles, rheumatism, oedema and irregular menstrual cycle [3]. Furthermore, studies have revealed that Garcinia cambogia has a prominent role in weight reduction. It has various phytochemicals such as terpenes, flavonoids and polyisoprenylated, benzophenone derivatives like garcinol, and xanthochymol. [4]. But the major constituent of Garcinia cambogia that plays an important role in weight loss is $\alpha-, \beta$ dihydroxy tricarboxylic acid (HCA) [5]. HCA inhibits the activity of ATP Citrate Lyase enzyme which causes the catalysis of mitochondrial cleavage of citrate to oxaloacetate and acetyl-coenzyme A (Acetyl-CoA), which is the building block of fatty acid synthesis citrate to Acetyl-CoA [6].

Coffee, native to Brazil, [7] contains several organic compounds such as caffeine, trigonelline and free sugars. Out of these organic compounds, Chlorogenic Acid, which is a major constituent of unroasted [8] and green coffee beans, is a great subject of interest to us. Studies reveal that chlorogenic acid enhances hormonal secretion as well as inhibits the conversion of Glucose 6 phosphate to glucose in the presence 
of hepatic glucose-6-phosphatase, which is a rate-limiting enzyme involved in gluconeogenesis, consequently aiding weight loss. [9, 10].

\section{Methods}

Our study consisted of 250 respondents, and the duration of the study was 12 weeks ( 3 months). Most of the respondents included in the trial were females who were unable to conceive due to having PCOS and were overweight. At the beginning of the trial, the height (feet) and weight $(\mathrm{kg})$ of every respondent were noted. For the treatment of obesity "Lite Plus" tablet was given to the respondents. "Lite Plus" consisted of a mixture of Garcinia Cambogia and Green Coffee Bean Extract as under:The quantity of Garcinia Cambogia extract was $500 \mathrm{mg}$ whereas, the amount of Green Coffee Bean Extract was $400 \mathrm{mg}$, respectively. The prescribed dosage of 'Lite Plus' was 2 tablets taken daily with or before meals for 3 months, while the dosage was amended accordingly for patients who were diabetic. Weekly changes (12 weeks) in the weight of every respondent were noted.

All subjects gave their informed consent for inclusion before they participated in the study. The study was conducted in accordance with the Declaration of Helsinki. IRB approval was taken from Jinnah Post Graduate Medical Center and approval number of JSMU/18/29-A.

To investigate the statistically significant changes in weight, analysis of variance (ANOVA) technique was applied. Least Significant Different (LSD) test at 5\% level of significance was used to check the significant differences among weekly means regarding weight and body mass index of the respondent. 


\section{Results}

Height

Height of the 250 respondents was taken for calculation of body mass index (BMI). The height of respondents was ranged from 4.00 feet to 6.00 feet. The average height of the respondents was found 5.33 feet with standard deviation of 0.272 feet. The histogram of height of the respondents was also drawn as figure 1

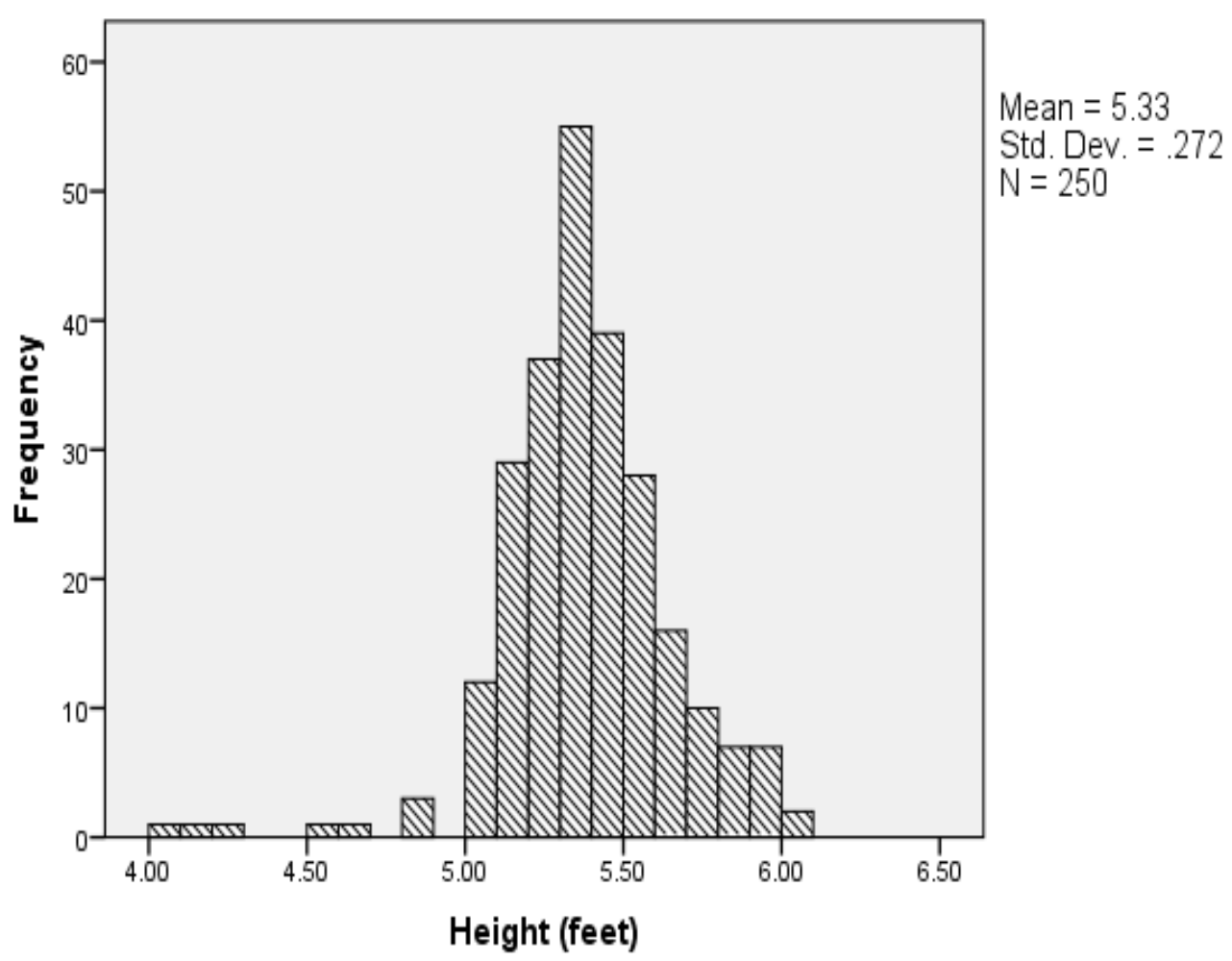

Figure 1: Histogram for height of 250 respondents 


\section{Weight}

Descriptive statistics (number of observations, minimum, maximum, mean, standard deviation and standard error) for weight of 250 respondents on weekly basis are given in Table $1 \mathrm{~B}$. It was observed from the table that at the $1^{\text {st }}$ week, minimum value of weight was $58.0 \mathrm{~kg}$ and maximum value was $135.0 \mathrm{~kg}$ with mean value of $84.91 \mathrm{~kg}$ (figure 2).

The histogram of weight of 250 respondents at $1^{\text {st }}$ week was as under:

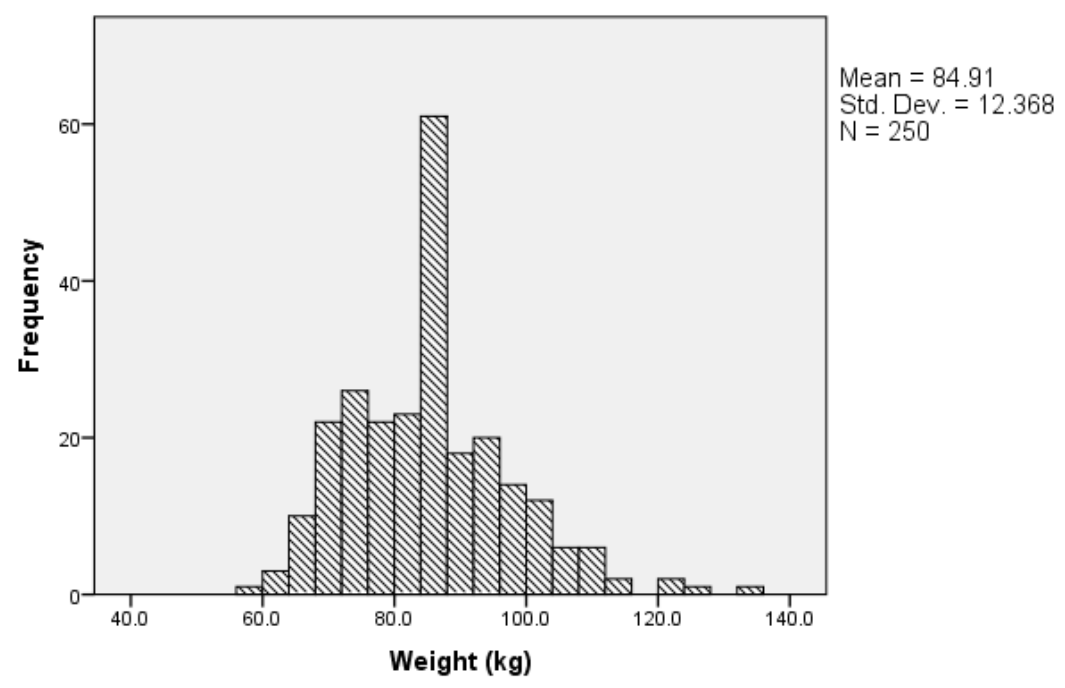

Histogram for weight of 250 respondents at week 1

The analysis of variance (ANOVA) table 1, which indicates that weekly body weight was highly significant $(\mathrm{P}<0.01)$ for different weeks by using "Lite Plus" tablets.

Table 1: $\quad$ Body weight of respondents

(A) Analysis of variance table

\begin{tabular}{lcccc}
\hline Source of variation & Degrees of freedom & Mean Square & F & Sig. \\
\hline Week & 11 & 1900.89 & $13.1 * *$ & 0.000 \\
Error & 2864 & 145.28 & & \\
Total & 2875 & & & \\
\hline
\end{tabular}

** = Highly significant $(\mathrm{P}<0.01)$ 
It is cleared that with increase in week, average weight of the respondents weekly decreased during the study period. Maximum mean weight $(84.91 \mathrm{~kg})$ was found at $1^{\text {st }}$ week of the study, which statistically remains same from week 2 to week 3 . At week 4 , the average weight $(82.24 \mathrm{~kg})$ decreased significantly as compared to week $1(84.91 \mathrm{~kg})$. From week 4 to week 6 , statistically no decrease in weight was found but at $7^{\text {th }}$ week, average weight of $79.95 \mathrm{~kg}$ was observed which was statistically different (decreased) from $4^{\text {th }}$ week. For the last 3 weeks, i.e., from week 10 to week 12 weight $(77.68 \mathrm{~kg}, 76.92 \mathrm{~kg}$ and $76.09 \mathrm{~kg}$, respectively) remains same statistically at $5 \%$ level of significance but different and less than from week 1 to week 7 (table 2).

(B) Descriptive statistics for weight of the respondents.

\begin{tabular}{lcccccc}
\hline Week & N & Min & Max & Mean & SD & SE \\
\hline w1 & 250 & 58.0 & 135.0 & $84.91 \mathrm{a}$ & 12.368 & 0.7823 \\
w2 & 250 & 57.0 & 135.0 & $84.06 \mathrm{ab}$ & 12.407 & 0.7847 \\
w3 & 250 & 56.0 & 134.0 & $83.14 \mathrm{abc}$ & 12.388 & 0.7835 \\
w4 & 250 & 55.0 & 133.0 & $82.24 \mathrm{bcd}$ & 12.369 & 0.7823 \\
w5 & 250 & 54.0 & 132.0 & $81.25 \mathrm{cde}$ & 12.335 & 0.7801 \\
w6 & 248 & 53.0 & 128.0 & $80.45 \mathrm{def}$ & 12.295 & 0.7808 \\
w7 & 242 & 56.0 & 125.0 & $79.95 \mathrm{ef}$ & 11.959 & 0.7688 \\
w8 & 240 & 55.0 & 120.0 & $79.10 \mathrm{fg}$ & 11.887 & 0.7673 \\
w9 & 229 & 54.0 & 119.0 & $78.64 \mathrm{fg}$ & 11.658 & 0.7704 \\
w10 & 224 & 54.0 & 117.0 & $77.68 \mathrm{gh}$ & 11.607 & 0.7755 \\
w11 & 222 & 53.0 & 117.0 & $76.92 \mathrm{gh}$ & 11.580 & 0.7772 \\
w12 & 221 & 53.0 & 116.0 & $76.09 \mathrm{~h}$ & 11.522 & 0.7750 \\
\hline
\end{tabular}

Min = Minimum value, Max = Maximum value, $\mathrm{SD}=$ Standard deviation, $\mathrm{SE}=$ Standard

The graphical presentation of the weekly change in average weight due to use of "Lite Plus" was given in Figure 3 and Figure 4 in the form of Box plot and Line plot, respectively. From these figures, it was also seen that with increase in time (weeks), the body weight was continuously decreased. 


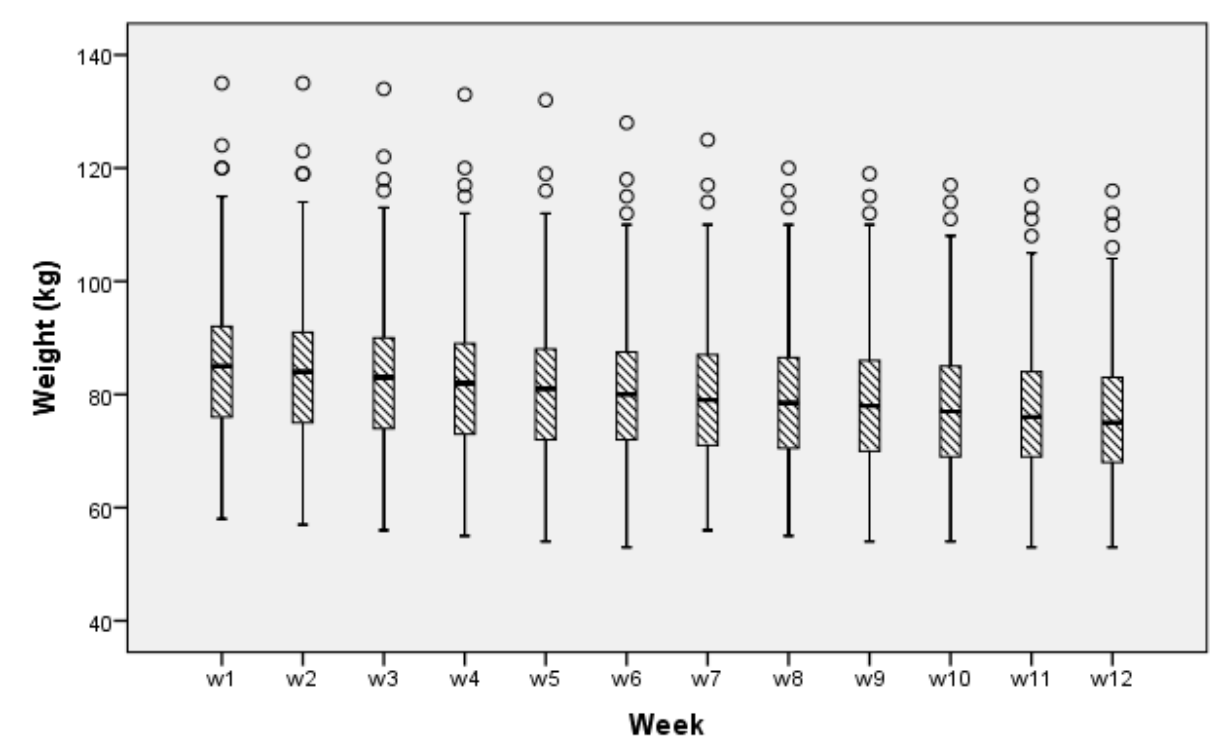

Figure 3. Box plot for weekly weight of respondents.

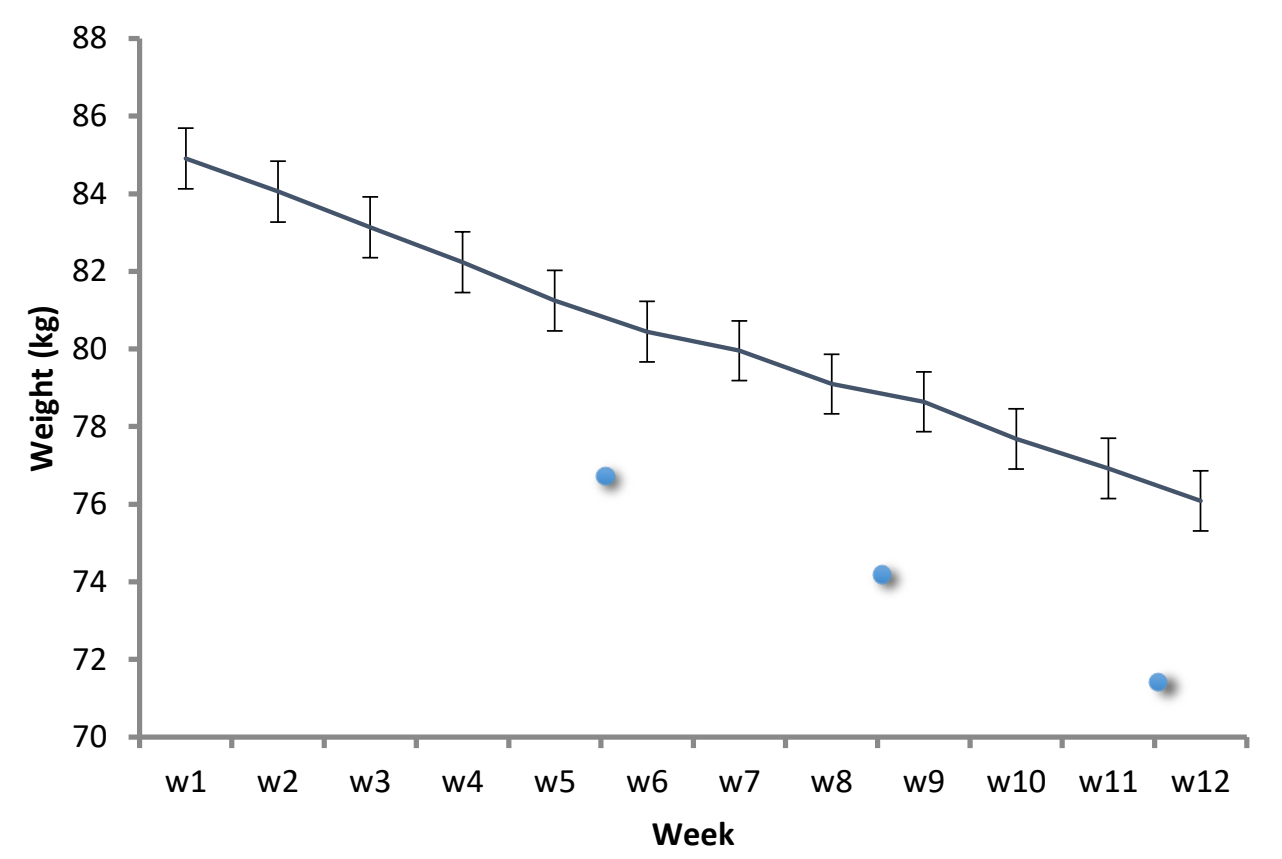

Figure 4. Graph showing the decrease in weekly mean weight of respondents due to use of "Lite Plus" tablet. 
The weekly details of weight loss $(\mathrm{kg})$ due to use of "Lite Plus" is given in Table 3.

Table 3: Weekly weight loss (due to use of "Lite Plus") in the respondents during the study (from week 2 to week 12)

(A) Analysis of variance table

\begin{tabular}{lcccc}
\hline Source of variation & Degrees of freedom & Mean Square & F & Sig. \\
\hline Week & 10 & 0.50276 & $3.47 * *$ & 0.0002 \\
Error & 2615 & 0.14499 & & \\
Total & 2625 & & \\
$* *$ = Highly significant $(\mathrm{P}<0.01)$ &
\end{tabular}

Analysis of variance shows highly significant $(\mathrm{P}<0.01)$ F-value. The comparison of means using Least Significant Different test was applied, which indicated that maximum decrease was found at week $5(0.99 \mathrm{~kg})$ which was non-significantly $(\mathrm{P}>0.05)$ different from week $6(0.926 \mathrm{~kg})$, week 7 $(0.985 \mathrm{~kg})$, week $8(0.991 \mathrm{~kg})$, week $9(0.985 \mathrm{~kg})$ and week $10(0.966 \mathrm{~kg})$. The lowest decrease in weight was found at $2^{\text {nd }}$ week $(0.854 \mathrm{~kg})$, which was statistically at par with $3^{\text {rd }}$, and $4^{\text {th }}$ weeks with mean values of $0.919 \mathrm{~kg}$ and $0.899 \mathrm{~kg}$, respectively (Table 4).

Table 4 Descriptive statistics with comparison of means

\begin{tabular}{lcccccc}
\hline Week & N & Min & Max & Mean & SD & SE \\
\hline w2 & 250 & -1.00 & 2.00 & $0.8538 \mathrm{~d}$ & 0.389 & 0.0246 \\
w3 & 250 & 0.00 & 3.00 & $0.9194 \mathrm{bcd}$ & 0.332 & 0.0210 \\
w4 & 250 & 0.00 & 2.00 & $0.8988 \mathrm{~cd}$ & 0.359 & 0.0227 \\
w5 & 250 & 0.00 & 3.50 & $0.9908 \mathrm{a}$ & 0.313 & 0.0198 \\
w6 & 248 & -1.00 & 4.00 & $0.9259 \mathrm{abc}$ & 0.378 & 0.0240 \\
w7 & 242 & -0.50 & 3.00 & $0.9850 \mathrm{ab}$ & 0.315 & 0.0202 \\
w8 & 240 & 0.00 & 5.00 & $0.9915 \mathrm{a}$ & 0.462 & 0.0298 \\
w9 & 229 & 0.00 & 6.00 & $0.9849 \mathrm{ab}$ & 0.576 & 0.0380 \\
\hline
\end{tabular}




\begin{tabular}{lllllll}
\hline w10 & 224 & 0.00 & 2.00 & $0.9665 \mathrm{abc}$ & 0.275 & 0.0184 \\
w11 & 222 & 0.00 & 2.00 & $0.9189 \mathrm{bcd}$ & 0.305 & 0.0205 \\
w12 & 221 & 0.00 & 3.00 & $0.9186 \mathrm{bcd}$ & 0.396 & 0.0267 \\
\hline
\end{tabular}

Min = Minimum value, Max = Maximum value, $\mathrm{SD}=$ Standard deviation, $\mathrm{SE}=$ Standard error

Means sharing similar letters in a column are statistically non-significant $(\mathrm{P}>0.05)$

The same results can be seen from Figure 5.

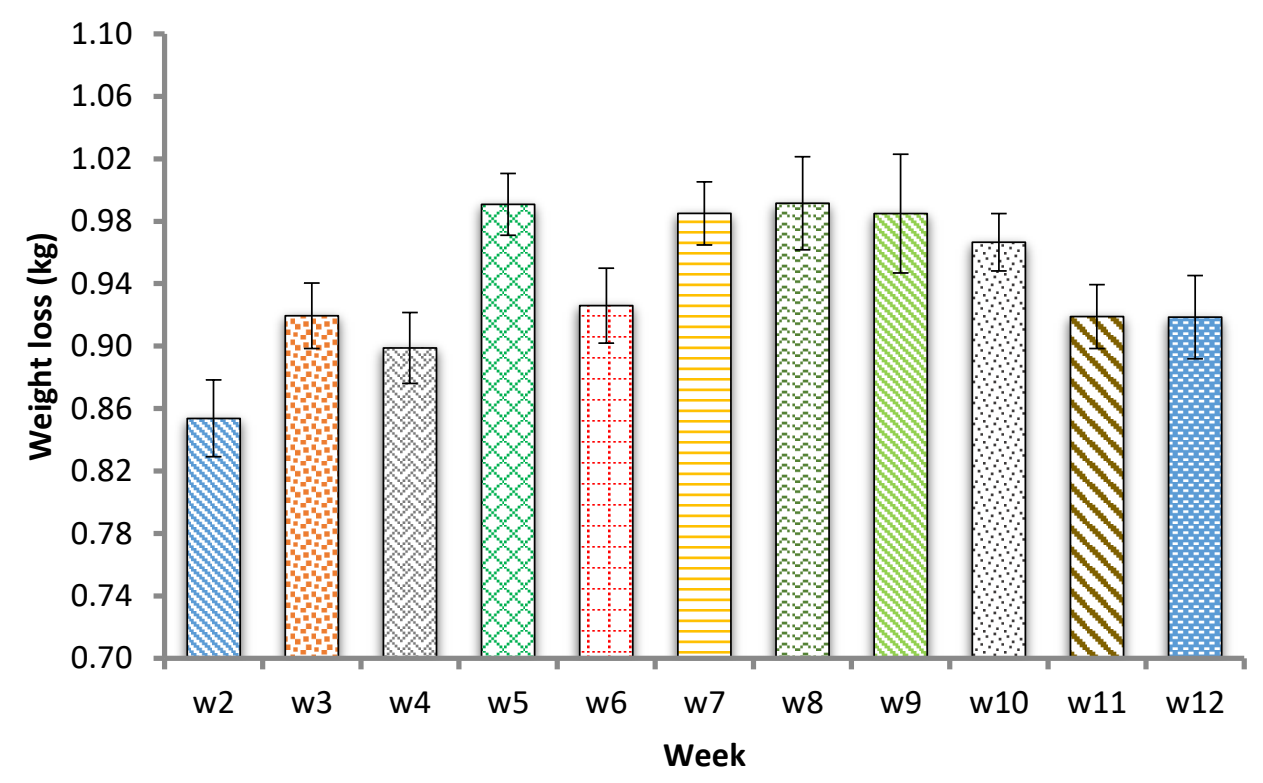

Fig. 4. Weekly weight loss $(\operatorname{mean} \pm \mathrm{SE})$ in respondents. 


\section{BMI (Body Mass Index)}

The main objective of our study was to reduce the body mass index (BMI) by using "Lite Plus" treatment (Garcinia Cambogia $500 \mathrm{mg}+$ Green Coffee Bean Extract $400 \mathrm{mg}$ ). For this purpose, a sample of 250 people (respondents) was selected and the 2 tablets of "Lite Plus" were given daily to these respondents from a period of 12 weeks ( 3 months). The histogram for body mass index (BMI) at the $1^{\text {st }}$ week is shown in figure 6.

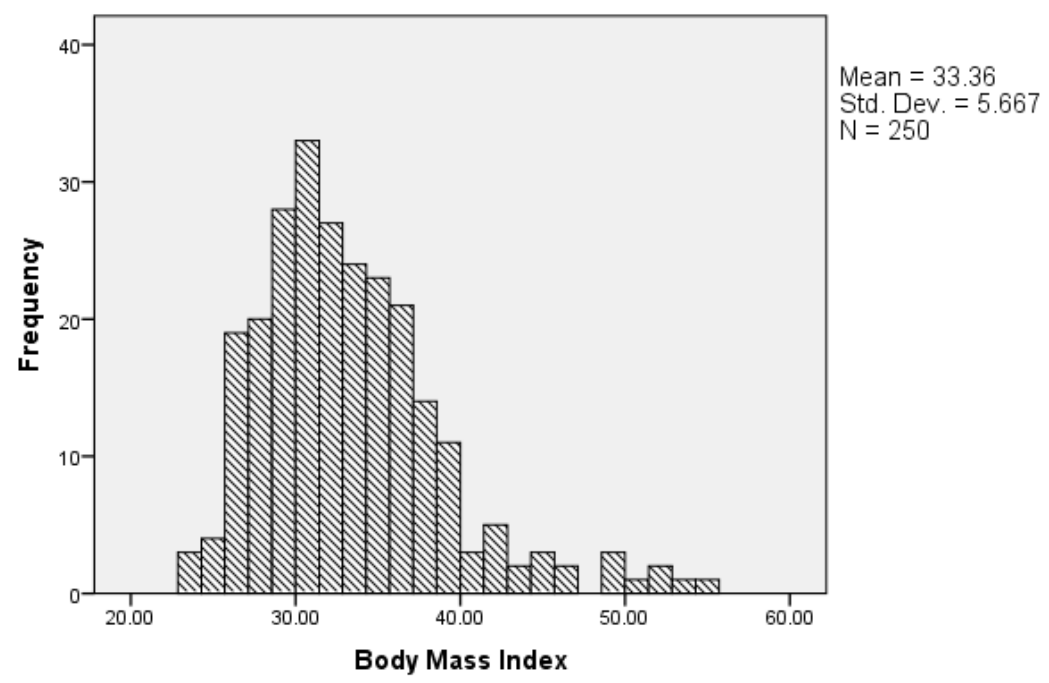

Histogram for BMI of 250 respondents at week 1

The number of observations $(\mathrm{N})$, minimum (Min), maximum (Max), mean, standard deviation (SD) and standard error (SE) of BMI was presented in Table 5 for $1^{\text {st }}$ to $12^{\text {th }}$ week.

(B) Descriptive statistics with comparison of means of BMI

\begin{tabular}{lcccccc}
\hline Week & N & Min & Max & Mean & SD & SE \\
\hline w1 & 250 & 23.39 & 55.52 & $33.36 \mathrm{a}$ & 5.667 & 0.3584 \\
w2 & 250 & 22.99 & 54.88 & $33.02 \mathrm{ab}$ & 5.656 & 0.3577 \\
w3 & 250 & 22.58 & 54.88 & $32.66 \mathrm{abc}$ & 5.638 & 0.3565 \\
w4 & 250 & 22.18 & 54.88 & $32.30 \mathrm{bcd}$ & 5.604 & 0.3544 \\
w5 & 21.78 & 54.23 & $31.91 \mathrm{cde}$ & 5.570 & 0.3523 \\
w6 & 250 & 21.37 & 53.59 & $31.62 \mathrm{def}$ & 5.519 & 0.3505 \\
w7 & 248 & 22.45 & 52.94 & $31.43 \mathrm{~d}-\mathrm{g}$ & 5.383 & 0.3460 \\
\hline
\end{tabular}




\begin{tabular}{lllllll}
\hline w8 & 240 & 22.10 & 52.29 & $31.10 \mathrm{e}-\mathrm{h}$ & 5.337 & 0.3445 \\
w9 & 229 & 21.75 & 51.65 & $30.88 \mathrm{f}-\mathrm{i}$ & 5.322 & 0.3517 \\
w10 & 224 & 21.41 & 51.00 & $30.54 \mathrm{ghi}$ & 5.312 & 0.3550 \\
w11 & 222 & 21.41 & 51.00 & $30.24 \mathrm{hi}$ & 5.290 & 0.3550 \\
w12 & 221 & 21.06 & 51.00 & $29.90 \mathrm{i}$ & 5.273 & 0.3547 \\
\hline
\end{tabular}

Min $=$ Minimum value, Max $=$ Maximum value, $\mathrm{SD}=$ Standard deviation, $\mathrm{SE}=$ Standard error

Means sharing similar letters in a column are statistically non-significant $(\mathrm{P}>0.05)$

At the start of the study, 250 respondents were taken and weekly weight was noted. During the study of 12 weeks, when a person gained the desired BMI value (i.e., normal in range), he was excluded from the study. By using this method, at the $6^{\text {th }}$ week, 2 respondents gained the desired BMI value and $248(250-2=248)$ respondents were left in the study. At the end of $7^{\text {th }}$ week, six more respondents reduced the desired level of BMI and 242 were remained in the study. Similarly, two respondents gained desired BMI level at $8^{\text {th }}$ week, 11 respondents gained normal BMI value at $9^{\text {th }}$ week and 5 were excluded from the study at $10^{\text {th }}$ week and at last 3 respondents were excluded from the study from week 11 to week 12. At the end of study, 29 respondents were gained desired level (excluded from the study) and 221 were left. The number of respondents who gain the desired level of BMI is shown in the following figure 7:

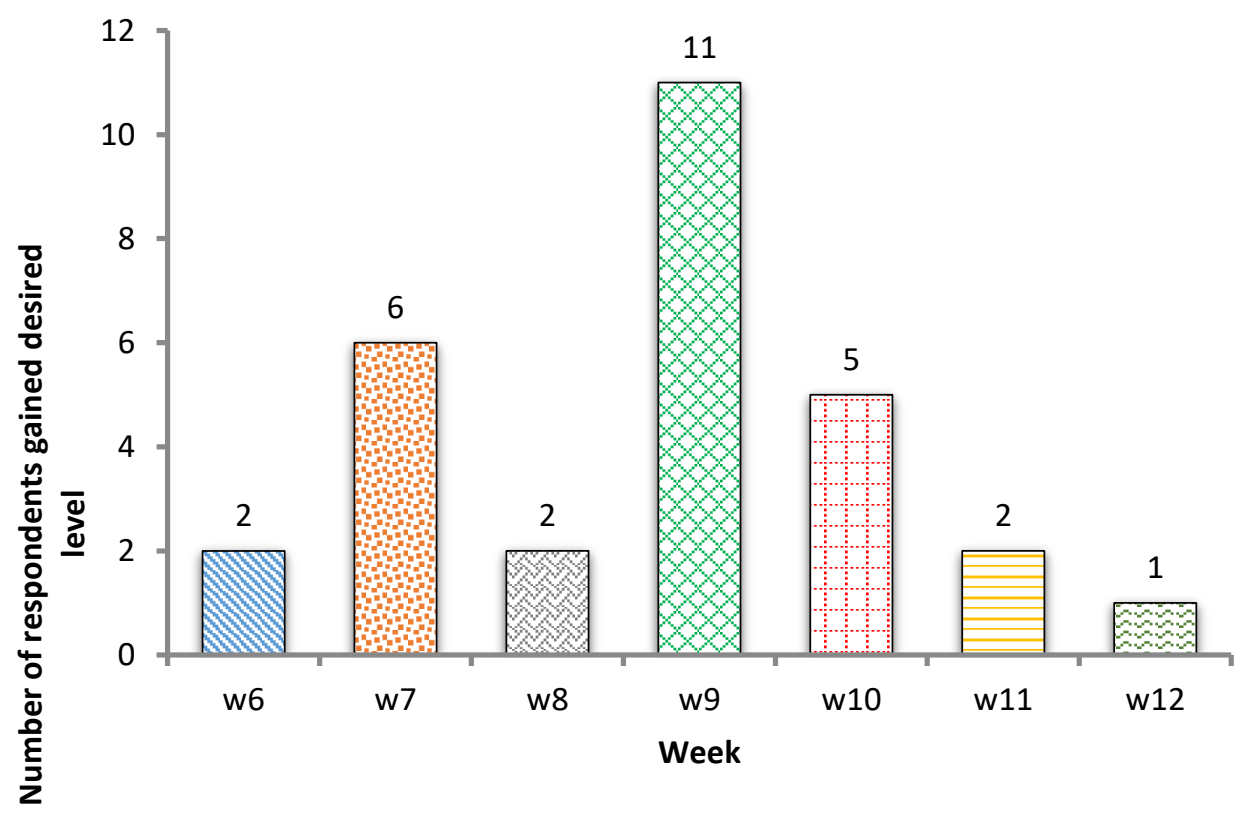


It was concluded from Table 5, that all the respondents were loss their weight /BMI gradually with the use of "Lite Plus" tablets. Descriptive statistics for total loss (from week 1 to week 12) in weight/BMI of respondents as below (table 6):

\begin{tabular}{lcccccc}
\hline from week 1 to week 12) & N & Min & Max & Mean & SD & SE \\
\hline Total weight loss & 250 & 3.00 & 20.00 & 9.883 & 2.189 & 0.138 \\
Total decrease in BMI & 250 & 1.14 & 7.81 & 3.897 & 0.968 & 0.061 \\
\hline
\end{tabular}

It was observed from Table 5 that the minimum mean value of BMI 23.39 was observed at the $1^{\text {st }}$ week of the study which was reduced to 21.06 at the $12^{\text {th }}$ week i.e., at the end of study, the minimum value of BMI was decreased by 2.33 and maximum value of was decreased by 4.42 from week 1 to week 12. Similarly, the mean value of BMI at first week was 33.36 with standard deviation of 5.67 and standard error of 0.358 reduced to mean value of BMI 29.90 at $12^{\text {th }}$ week with standard deviation of 5.27 and standard error of 0.355 .

The analysis of variance table showed a highly significant $(\mathrm{P}<0.01)$ F-value (9.69) for BMI (body mass index) in the respondents (Table 7), which indicated that statistically BMI value not remained the same during different weeks.

Table 7: $\quad$ Analysis of variance for BMI

\begin{tabular}{lcccc}
\hline Source of variation & Degrees of freedom & Mean Square & F & Sig. \\
\hline Week & 11 & 290.185 & $9.69 * *$ & 0.0000 \\
Error & 2864 & 29.955 & \\
Total & 2875 & & \\
$* *=$ Highly significant $(\mathrm{P}<0.01)$ &
\end{tabular}

The Least Significant Different (LSD) test was applied and given in the "Mean" column of Table 5 in the form of small alphabets. From the "Mean" column, it was cleared that the maximum mean value of BMI (33.36) was found at the start of the experiment at $1^{\text {st }}$ week which was nonsignificantly $(\mathrm{P}>0.05)$ different from $2^{\text {nd }}$ and $3^{\text {rd }}$ weeks but statistically significantly higher than 
from week 4 to week 12 . After $4^{\text {th }}$ week BMI was statistically remained same till $7^{\text {th }}$ week i.e., statistically no change (increase or decrease) was found during this period. The minimum value 29.90 with standard deviation 5.27 of BMI was observed at last i.e., $12^{\text {th }}$ week which was statistically at par with week 9, week 10 and week 11 with mean values of 31.10, 30.54 and 30.24, respectively.

Box plot for BMI was given in Figure 8 , which showed the decreasing trend in BMI with increase in week i.e., as "Lite Plus" was used by the respondents, body mass index (BMI) gradually decreased, which was the indication of the success of our treatment.

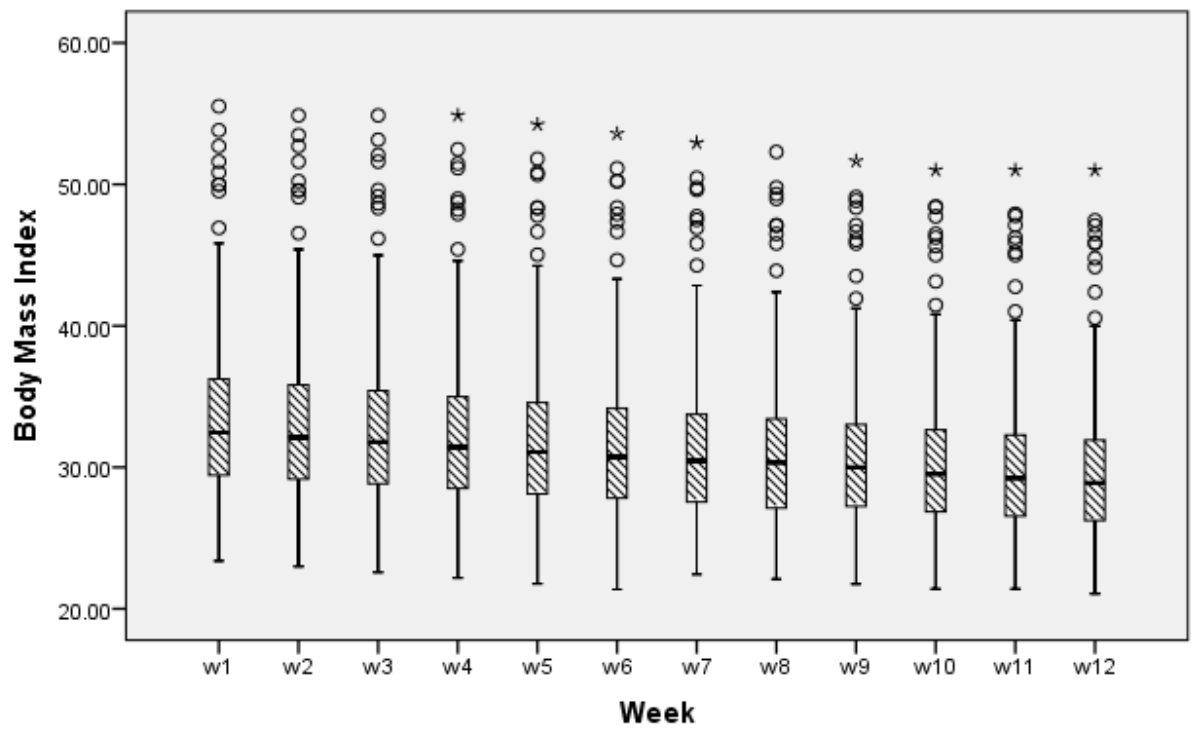

Fig. 6: $\quad$ Box plot for weekly Body Mass Index of respondents.

A linear regression was also applied to see the change in body mass index (BMI) with time (weeks). The graph showed a decreasing linear trend with $\mathrm{R}^{2}$ (coefficient of determination) value of $99.62 \%$, which was a very strong indicator of goodness of fit of the linear model. The following linear regression was found

$\mathrm{Y}=33.57-0.3065 \mathrm{X}$

Where $\mathrm{Y}=\mathrm{BMI}$ (body mass index) $\mathrm{X}=$ weeks 
The regression equation given in equation (1) showed with increase in one week, the BMI was decreased by 0.3065 . The constant value of the model showed that the value of BMI was 33.57 at week 0 (before start of the experiment) (figure 9)

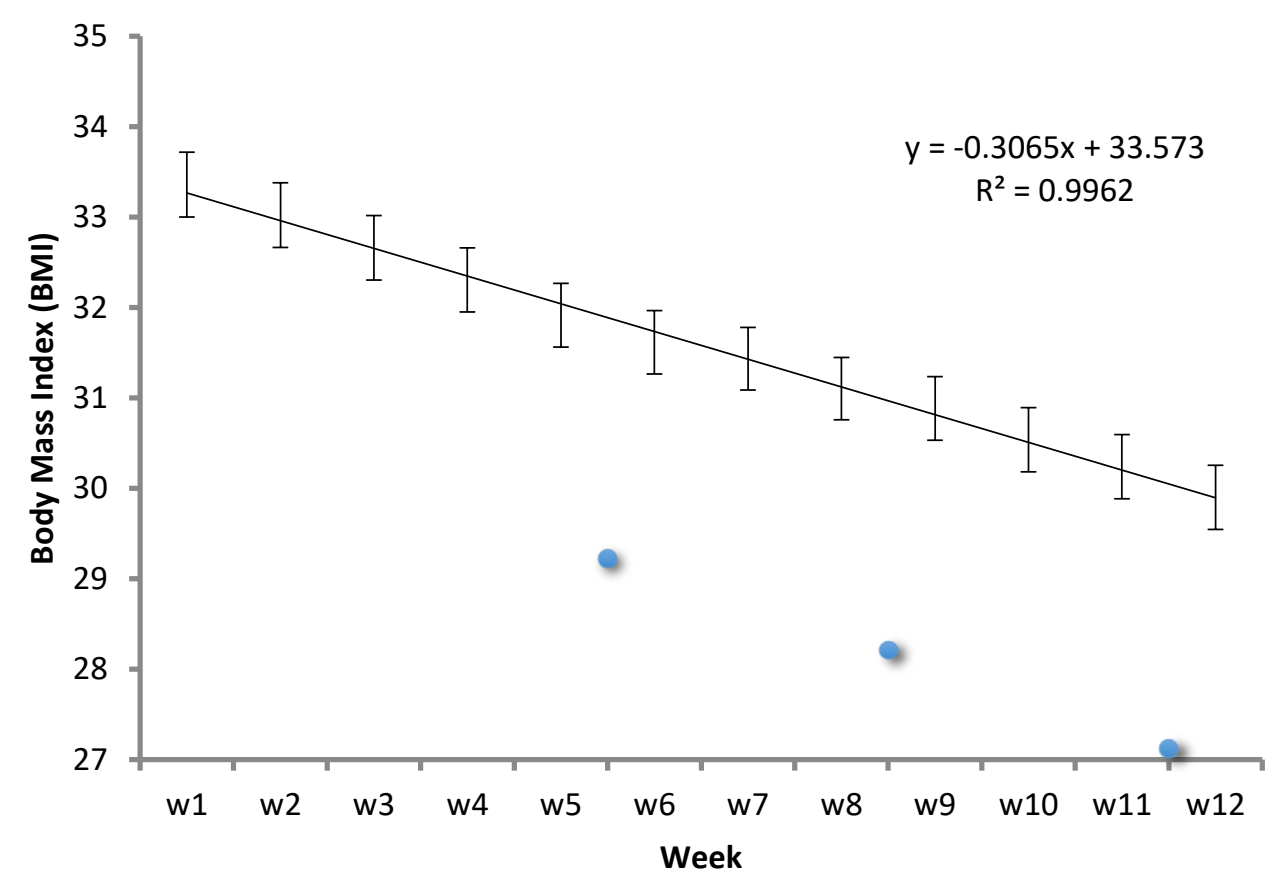

Fig. 7: Graph showing the weekly change in mean BMI of respondents due to "Lite Plus" treatment with linear regression line.

The analysis of variance Table 8 for weekly decrease in body mass index showed significant $(\mathrm{P}<0.05)$ results. 
Table 8: $\quad$ Weekly decrease in Body Mass Index (BMI) of the respondents (from week 2 to week 12)

\begin{tabular}{lcccc}
\hline Source of variation & Degrees of freedom & Mean Square & F & Sig. \\
\hline Week & 10 & 0.07602 & $3.22^{* *}$ & 0.0004 \\
Error & 2615 & 0.02360 & & \\
Total & 2625 & & \\
\hline NS = Non-significant $(\mathrm{P}>0.05)$ &
\end{tabular}

On the other hand, Least Significant Different (LSD) test showed that maximum decrease (0.391) was found at $8^{\text {th }}$ week which statistically significantly different from $11^{\text {th }}(0.362)$ and $12^{\text {th }}(0.361)$ weeks but non-significantly different from all other weeks i.e., week 5, week 6, week 7, week 9 and week 10 (Table 9).

Table 9 Descriptive statistics for BMI of the respondents

\begin{tabular}{lcccccc}
\hline Week & N & Min & Max & Mean & SD & SE \\
\hline w2 & 250 & -0.37 & 0.83 & $0.337 \mathrm{~d}$ & 0.157 & 0.010 \\
w3 & 250 & 0.00 & 1.25 & $0.361 \mathrm{bcd}$ & 0.137 & 0.009 \\
w4 & 250 & 0.00 & 0.83 & $0.356 \mathrm{~cd}$ & 0.148 & 0.009 \\
w5 & 250 & 0.00 & 1.25 & $0.390 \mathrm{a}$ & 0.128 & 0.008 \\
w6 & 248 & -0.37 & 1.34 & $0.366 \mathrm{abc}$ & 0.149 & 0.009 \\
w7 & 242 & -0.20 & 1.01 & $0.389 \mathrm{ab}$ & 0.129 & 0.008 \\
w8 & 240 & 0.00 & 1.95 & $0.391 \mathrm{a}$ & 0.180 & 0.012 \\
w9 & 229 & 0.00 & 2.34 & $0.387 \mathrm{ab}$ & 0.226 & 0.015 \\
w10 & 224 & 0.00 & 0.83 & $0.382 \mathrm{abc}$ & 0.118 & 0.008 \\
w11 & 222 & 0.00 & 0.83 & $0.362 \mathrm{bcd}$ & 0.129 & 0.009 \\
w12 & 221 & 0.00 & 1.14 & $0.361 \mathrm{bc}$ & 0.160 & 0.011 \\
\hline
\end{tabular}

Min = Minimum value, Max = Maximum value, $\mathrm{SD}=$ Standard deviation, $\mathrm{SE}=$ Standard error 
Means sharing similar letters in a column are statistically non-significant $(\mathrm{P}>0.05)$

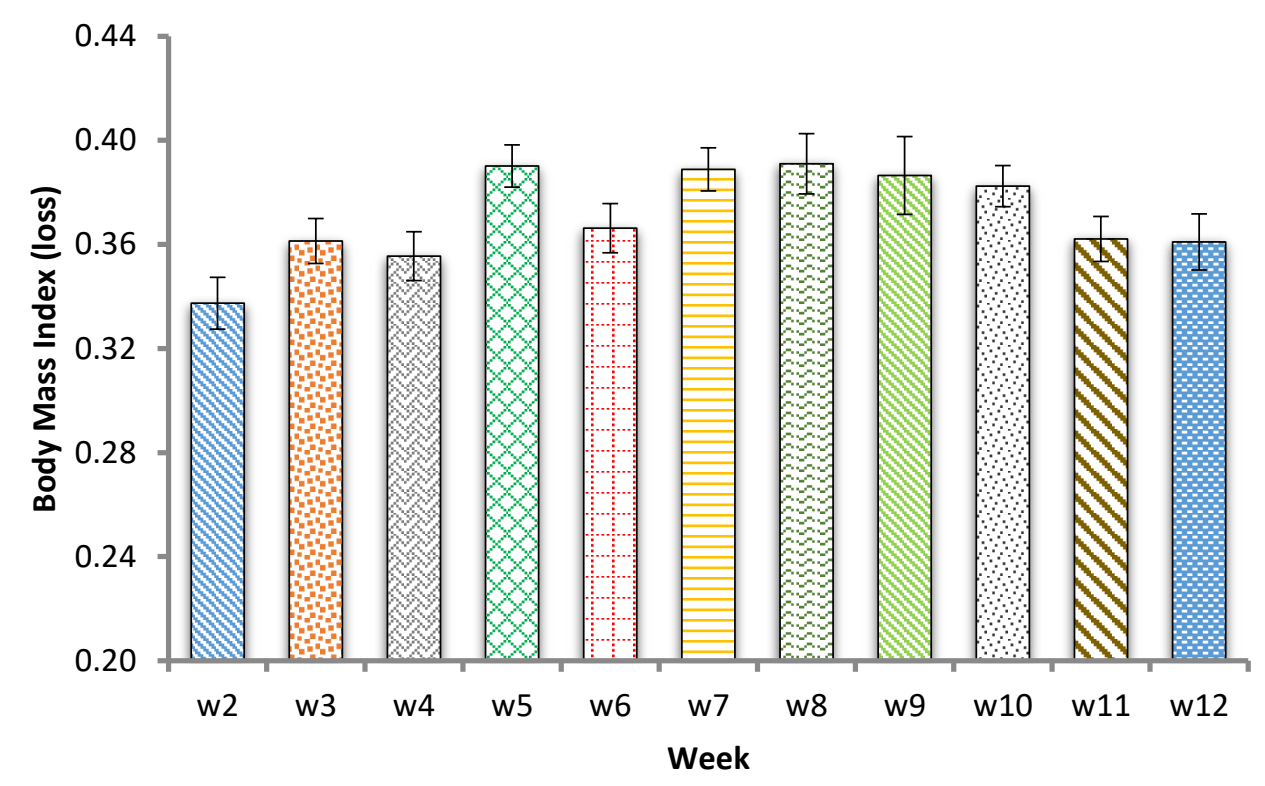

Fig. 8: Weekly decrease in Body Mass Index (mean \pm SE) due to "Lite Plus".

\section{Discussion:}

Obesity has been associated with a number of conditions like fatty liver disease, osteoarthritis, digestive problems, cardiovascular disease, type II Diabetes Mellitus, and even some forms of cancer [11]. Along with its consequent comorbidities, obesity represents a socio-economic burden which has been shown to reduce life expectancy significantly. To tackle this problem, several strategies have been proposed, out of which caloric restriction combined with exercise is the most commonly used one. In cases of extreme obesity, surgical intervention has been recommended [12]. Pharmacological obesity treatment is principled by the ESCP Guideline, according to which it should be only intended for patients with a BMI > 30 or BMI > 27 with comorbidity [13]. Considering the potential side effects of anti-obesity drugs, they should be prescribed only when the benefits outweigh the risks.

In the face of the many reported adverse effects of synthetic drugs, the choice of natural products is much more preferable due to their effectiveness in managing obesity with minimal side effects. For instance, traditional herbal medicines have a long history of use in suppressing appetite and promoting weight loss and have little to none toxic effects when compared to synthetic ones [14]. Going by this theory, we studied the role in weightloss of alternative natural medicine (Garcinia 
cambogia and green coffee beans) in this study, and we found that $92.8 \%$ of participants experienced weight loss after using Garcinia cambogia and green coffee bean extract for 6 weeks. After 12 weeks of use, $11.6 \%$ of participants reached their desired BMI.

To the best of our knowledge, this study trial is the first of its kind to research the combined role of Garcinia cambogia and green coffee bean extract in weight loss. Several reports support that the administration of Garcia cambogia reduces weight; however, not much evidence is available on its long term effects. Some reported minor side effects might be related to the different compositions of administered GC extracts [11]. A meta-analysis showed that the reported adverse effects were similar to placebo, and it is safe for human consumption [15]. Similarly, the metaanalysis indicates the effectiveness of green coffee bean extract in weight loss [9].

In summary, obesity is a complex, chronic disorder caused by an amalgamation of factors like diet, lifestyle, genetic and environmental. Appropriate lifestyle and dietary modifications are the fundamentals of successful weight loss but maintaining such a lifestyle can prove to be challenging. Therefore, it is important to identify the herbs and natural products which can promote weight loss while being safe for human consumption.

\section{Conclusion:}

This study identifies that the combined use of Garcia cambogia with green coffee bean extract can effectively promote weight loss with minimal adverse effects. This study also raises the possibility that the combination of multiple natural products can produce a synergistic effect which increases their individual anti-obesity action on different targets, thus offering a distinct advantage over chemical treatments. Natural products may give not only an anti-obesity effect but also other health benefits like anti-diabetic and anti-hyperlipidemic activities. In light of our findings, we anticipate that natural sources will provide a beneficial basis for developing novel anti-obesity drugs in the future.

\section{References}

1. Consultation WH. OBESI'I'Y: PREVENTING AND MANAGING THE GLOBAL EPIDEMIC. https://www.researchgate.net/profile/Sebastiao Almeida3/publication/273291964 Imagem C orporal Ansiedade e Depressao em Mulheres Submetidas a Cirurgia Bariatrica/links/55f1c 5a308ae199d47c475c7.pdf

2. National Nutrition Survey, 2018 https://www.unicef.org/pakistan/reports/nationalnutrition-survey-2018-key-findingsreport\#: :text=The\%202018\%20Pakistan\%20National\%20Nutrition,environmental\%2C\%20a nthropometric\%20and\%20biochemical\%20indicators. 
3. Chuah LO, Ho WY, Beh BK, Yeap SK. Updates on anti-obesity effect of garcinia origin (-)HCA. Evid Based Complement Alternat Med. 2013;2013:751658. $10.1155 / 2013 / 751658$.

4. Hemshekhar M, Sunitha K, Santhosh MS, Devaraja S, Kemparaju K, Vishwanath BS, Niranjana SR, Girish KS. An overview on genus Garcinia: phytochemical and therapeutical aspects. Phytochemistry Reviews. 2011;10(3):325-51. 10.1007/s11101-011-9207-3

5. Ohia SE, Opere CA, LeDay AM, Bagchi M, Bagchi D, Stohs SJ. Safety and mechanism of appetite suppression by a novel hydroxycitric acid extract (HCA-SX). Molecular and cellular biochemistry. 2002;238(1-2):89-103. 10.1023/A:1019911205672

6. Semwal RB, Semwal DK, Vermaak I, Viljoen A. A comprehensive scientific overview of Garcinia cambogia. Fitoterapia. 2015;102:134-48.10.1016/j.fitote.2015.02.012

7. Souza HN, Cardoso IM, Fernandes JM, Garcia FC, Bonfim VR, Santos AC, Carvalho AF, Mendonça ES. Selection of native trees for intercropping with coffee in the Atlantic Rainforest biome. Agroforestry systems. 2010;80(1):1-6. 10.1007/s10457-010-9340-9

8. Wei F, Tanokura M. Organic compounds in green coffee beans. In Coffee in Health and Disease Prevention 2015. (pp. 149-162). Academic Press.10.1016/B978-0-12409517-5.00017-6

9. Onakpoya I, Terry R, Ernst E. The use of green coffee extract as a weight loss supplement: a systematic review and meta-analysis of randomised clinical trials. Gastroenterol Res Pract. 2011;2011:382852. 10.1155/2011/382852.

10. Arion WJ, Canfield WK, Ramos FC, et al. Chlorogenic acid and hydroxynitrobenzaldehyde: new inhibitors of hepatic glucose 6-phosphatase. Archives of biochemistry and biophysics. 1997;339(2):315-22.10.1006/abbi.1996.9874 http://www.sidalc.net/cgi$\underline{\text { bin/wxis.exe/?IsisScript=ACERVO.xis\&method=post\&formato=2\&cantidad=1\&expresion=mf }}$ $\underline{\mathrm{n}=048115}$

11. Maia-Landim A, Ramírez JM, Lancho C, Poblador MS, Lancho JL. Long-term effects of Garcinia cambogia/Glucomannan on weight loss in people with obesity, PLIN4, FTO and 
Trp64Arg polymorphisms. BMC Complement Altern Med. 2018 Jan 24;18(1):26. doi: 10.1186/s12906-018-2099-7

12. MacLean PS, Wing RR, Davidson T, Epstein L, Goodpaster B, Hall KD, et al. NIH working group report: innovative research to improve maintenance of weight loss. Obesity. 2015;23:7-15. doi: 10.1002/oby.20967

13. Apovian C.M., Aronne L.J., Bessesen D.H., McDonnell M.E., Murad M.H., Pagotto U., Ryan D.H., Still C.D. Pharmacological management of obesity: An endocrine society clinical practice guideline. J. Clin. Endocr. Metab. 2015;100:342-362. doi: 10.1210/jc.2014-3415.

14. Chandrasekaran C.V., Vijayalakshmi M.A., Prakash K., Bansal V.S., Meenakshi J., Amit A. Review article: Herbal approach for obesity Management. Am. J. Plant Sci. 2012;3:10031014. doi: 10.4236/ajps.2012.327119.

15. Onakpoya I, Hung SK, Perry R, Wider B, Ernst E. The Use of Garcinia Extract (Hydroxycitric Acid) as a Weight loss Supplement: A Systematic Review and Meta-Analysis of Randomised Clinical Trials. J Obes. 2011;2011:509038. 10.1155/2011/509038. 